\title{
Molecular Cloning of cDNA for a Novel Pea Dof Protein, PsDof1, and Its DNA - Binding Activity to the Promoter of PsDof1 Gene
}

\author{
Hikaru SEKI ${ }^{\ddagger}$, Naoki NAKAMURA, Mizuri MARUTANI, Takeharu OKABE, Shiroh SANEMATSU, \\ Yoshishige INAGAKI, Kazuhiro TOYODA, Tomonori SHIRAISHI, Tetsuji YAMADA and Yuki ICHINOSE* \\ Laboratory of Plant Pathology \& Genetic Engineering, Faculty of Agriculture, Okayama University, \\ Tsushima-naka 1-1-1, Okayama 700-8530, Japan \\ ${ }^{\ddagger}$ Present address:Plant Science Center, RIKEN, Wako-shi, Saitama 351-0198, Japan \\ *Corresponding author E-mail address: yuki@cc.okayama-u.ac.jp
}

Received 25 April 2002; accepted 24 June 2002

\begin{abstract}
A cDNA clone, designated PsDof1, encoding a novel member of the Dof DNA-binding protein family was isolated from pea. Random-binding-site selection and gel retardation experiments showed that the GST-PsDof1 recombinant protein bound to specific DNA sequences with an AAAG core. A metal-chelating agent, 1,10-phenanthroline, abolished binding of GST-PsDof1 to DNA, but the addition of $\mathrm{Zn}^{2+}$ restored it, indicating that zinc ions are required for its DNA-binding activity. Interestingly, there are possible sites for binding PsDof 1 in its promoter sequence. Indeed, GST-PsDof1 binds to the AAAG-containing promoter sequence of the PSDof1 gene with higher affinity. These results suggest that PsDof1 is a novel transcription factor that is involved in its own transcriptional regulation.
\end{abstract}

Key words: Autoregulation, DNA- binding protein, Dof protein, Pisum sativum, Promoter, Transcription factor, Zinc- finger protein

\begin{abstract}
Abbreviations
Dof, DNA binding with one finger; GST, glutathione S-transferase; PCR, polymerase chain reaction
\end{abstract}

\section{Introduction}

Dof (DNA binding with one finger) proteins belong to the family of zinc-finger transcription factors in plants. All Dof proteins that have been analyzed conserve a 52-amino-acid stretch called the Dof domain that contains a $\mathrm{CX}_{2} \mathrm{CX}_{21} \mathrm{CX}_{2} \mathrm{C}$ putative zinc-finger motif near the $\mathrm{N}$-terminus; in contrast, the regions outside the Dof domain have little or no homology to each other and show no significant homology to any sequence found in protein databases (Kisu et al., 1998; Takatsuji, 1998). Interestingly, genes encoding Dof proteins (Dof genes) are found only in higher plants - they are not found in either yeast or Caenorhabditis elegans genomes (Riechmann et al., 2000). These finding suggest that Dof proteins regulate the genes required for a wide variety of plant-specific functions, including metabolism and differentiation.
Therefore, characterization of the Dof protein attracted us to the study of the transcriptional regulation of plant-specific functions.

The first member of this protein family, Dof1, was identified from maize as the protein that specifically bound to an AAGG motif in the cauliflower mosaic virus $35 \mathrm{~S}$ promoter (Yanagisawa and Izui, 1993). Since this finding, the role of Dof proteins has been studied in only a few members of that family. Several functions of Dof proteins have been reported: involvement in light-regulated gene expression in maize Dof1 and Dof2 (Yanagisawa and Sheen, 1998), gene activation of storage proteins in maize and barley PBF (Vicente Carbajosa et al, 1997; Mena et al., 1998), regulation of rolB oncogene expression in tobacco BBF (De Paolis et al., 1996; Baumann et al., 1999), regulation of stressrelated genes in Arabidopsis OBP1 (Kang and Singh, 2000), and regulation of seed germination in Arabidopsis DAG1 (Papi et al., 2000). Genomic-sequence analysis in Arabidopsis revealed the presence of 37 members of the Dof gene family (Riechmann et al., 2000). However, the function of gene products has been investigated in only several Dof genes, such as OBP1 and DAG1 (Kang and 
Singh, 2000; Papi et al., 2000); thus most Dof genes remain to be analyzed. Furthermore, no promoter analysis of Dof genes has yet been performed. Because Dof proteins are transcription factors, analysis of the transcriptional regulation of Dof genes should provide novel information for elucidation of the transcriptional hierarchy.

In this study, we identified the pea Dof gene PSDof 1 from an elicitor-treated cDNA library. We further characterized the DNA-binding activity of PsDof1 protein. We found that PsDof1 protein binds to both sequences with an AAAG core and to the AAAG-containing promoter sequence of the PSDof1 gene itself, which suggests transcriptional autoregulation. Because the corresponding cDNA clone was isolated from elicitor-treated pea epicotyls, we also discuss the possible function of PsDof1 in defense responses.

\section{Materials and Methods}

Isolation of $\mathrm{CDNA}$ and genomic clones for PSDof1 gene

A pea (Pisum sativum L. cv. Midoriusui) cDNA library was constructed from fungal elicitor-treated epicotyls for $5 \mathrm{~h}$ as previously described (Ichinose et al., 2001). The E84 cDNA clone was isolated as a candidate for elicitor-inducible cDNA clone by differential screening (Ichinose et al., 2001), and renamed PsDof1 according to its sequencing information.

The PSDofI gene was initially isolated from a commercially available pea genomic DNA library (Stratagene, La Jolla, CA, USA). To further isolate the PsDof1 gene from the pea cultivar Midoriusui, polymerase chain reaction (PCR) was carried out using genomic DNA as the template. PCR primers (P1: 5' GCCCAAAAGCAAATAATATCAG-3'; P2: 5' CTTCCTACACCCGCCACCAA-3') were designed by the sequence in the PSDof1 gene from the genomic DNA library.

The nucleotide sequences were determined with a DNA sequencer (ABI PRISM ${ }^{\mathrm{TM}}$ 310, PE Applied Biosystems, Chiba, Japan) using the BIG Dye ${ }^{T M}$ Terminator Cycle Sequencing kit. The homology search was performed with the BLAST search protocol.

Expression of recombinant PsDof1 in Escherichia coli

The recombinant plasmid for expression of a fusion protein of glutathione $\mathrm{S}$ - transferase (GST) and PsDof1 was constructed using the pGEX $-5 X-1$ vector (Amersham Pharmacia Biotech, Tokyo, Japan). The entire coding region of PsDof1 was amplified by PCR with the following primers: 5 '. ccgaattcATGGATCCTTCTTCTCAGCA - 3' and 5' - ccctcgagCATTAGAGGACTATGAAGAA-3'; lower-case nucleotides were added to restrict digestion after PCR amplification, underlined sequences are the recognition sites for $E c o$ RI and XhoI (the ATG codon for the first methionine in PsDof1 is in italics). The resulting DNA fragment was inserted into a pGEX-5X-1 vector, then transformed into the $E$. coli strain BL21.

$E$. coli cells containing the chimeric construct were grown in $300 \mathrm{ml}$ of $2 \times \mathrm{YT}$ medium at $37^{\circ} \mathrm{C}$ to the mid- $\log$ phase. The expression of fusion protein was induced with $1 \mathrm{mM}$ isopropyl $\beta$-D-thiogalactopyranoside at $30{ }^{\circ} \mathrm{C}$ for $2 \mathrm{~h}$. Cells were harvested by centrifugation, resuspended in $10 \mathrm{ml}$ of $\mathrm{PBS}$ buffer $\left(140 \mathrm{mM} \mathrm{NaCl}, 2.7 \mathrm{mM} \mathrm{KCl}, 10 \mathrm{mM} \mathrm{Na}_{2}\right.$ $\mathrm{HPO}_{4}, 1.8 \mathrm{mM} \mathrm{KH} \mathrm{PO}_{4}$; pH 7.3). Phenylmethylsulfonylfluoride and Triton $\mathrm{X}-100$ were added to final concentrations of $1 \mathrm{mM}$ and $1 \%$, respectively. The cells were sonicated five times each for $15 \mathrm{~s}$ on ice, and centrifuged at $12,000 \mathrm{~g}$ for $15 \mathrm{~min}$. The supernatant was mixed with $300 \mu 1$ of $50 \%$ glutathioneSepharose 4B (Amersham Pharmacia Biotech) slurry, and incubated at $4{ }^{\circ} \mathrm{C}$ for $30 \mathrm{~min}$. The Sepharose beads were recovered by low centrifugation $(<1,000 \mathrm{~g}, 3 \mathrm{~min})$ and washed three times with PBS buffer. Then the GST-PsDof1 fusion protein bound to glutathione-Sepharose beads was resuspended in $1 \mathrm{x}$ binding buffer $(25 \mathrm{mM}$ HEPES-KOH, $100 \mathrm{mM}$ $\mathrm{KCl}, 10 \mu \mathrm{M} \mathrm{ZnSO}_{4}, 1 \mathrm{mM}$ DTT, $0.1 \% \mathrm{NP} 40,5 \%$ glycerol; $\mathrm{pH} 7.5$ ) and used directly for random binding-site selection assay. For the electrophoretic mobility-shift assay, GST-PsDof1 fusion protein was eluted from the beads by incubation for $20 \mathrm{~min}$ with $50 \mathrm{mM}$ Tris $-\mathrm{HCl}$ (pH 8.0) containing $10 \mathrm{mM}$ reduced glutathione.

\section{Binding - site selection assay}

A 56-bp DNA mixture was made with 10-ng of 56-mer synthetic DNA (5'-AAGCTTCTAGAGATCCGTCA - $\mathbf{N}_{16}$ - CACAATCCCACTATCCTTCG $-3^{\prime}$ ) as an initial template, two $0.2 \mu \mathrm{M}$ primers (F: 5'-AAGCTTCTAGAGATCCGTCA-3'; R: 5' CGAAGGATAGTGGGATTGTG-3'), and $47 \mu 1$ of Super Taq premix kit (SAWADY, Tokyo, Japan). The amplified DNA sequences contained 16 random nucleotides flanked by the defined sequence, and they were used as the source of the initial PsDof1 for the binding-site selection assay. Amplification was carried out for 25 cycles in a volume of $50 \mu \mathrm{l}$, and then the first round of capture was initiated using the amplified dsDNA without further purification. For the first round of capture, $2 \mu 1$ of amplified PCR mixture was mixed with $10 \mu \mathrm{g}$ of 
GST - PsDof1 bound to glutathione-Sepharose beads in $100 \mu 1$ of $1 \mathrm{x}$ binding buffer $(25 \mathrm{mM}$ HEPES- $\mathrm{KOH}, 100 \mathrm{mM} \mathrm{KCl}, 10 \mu \mathrm{M} \mathrm{ZnSO}_{4}, 1 \mathrm{mM}$ DTT, $0.1 \%$ NP40, 5\% glycerol; pH 7.5) containing $5 \mu \mathrm{g}$ of poly (dI-dC:dI-dC), which was included in all of the rounds of capture as a nonspecific competitor. This mixture was incubated at $4{ }^{\circ} \mathrm{C}$ for $30 \mathrm{~min}$ whilst rotating continuously. The GST-PsDof1DNA complexes on beads were collected by centrifugation at $1,000 \mathrm{~g}$ for $30 \mathrm{~s}$; the pellet was then resuspended and washed seven times with $1 \mathrm{ml}$ of 1 $\mathrm{x}$ binding buffer. The bound DNA was extracted from the GST-PSDof1 on beads as described by Hyde-DeRuyscher et al. (1995) with slight modifications. The DNA was resuspended in $20 \mu \mathrm{l}$ of $\mathrm{H}_{2} \mathrm{O}$, and $1 \mu \mathrm{l}$ of this was used for amplification. After six rounds of selection, the amplified DNA was cloned into a PCRII- TOPO vector (Invitrogen, Carlsbad, CA, USA), and 16 independent clones were sequenced. Strikingly, all selected DNAs contained an AAAG sequence (data not shown), suggesting that this sequence is the recognition core of PsDof1 protein. Thus, to investigate whether the PsDof1 exhibited binding preferences for the sequences flanking the AAAG core, we carried out a second binding-site selection experiment with DNAs carrying a prefixed AAAG core flanked by six random nucleotides. A 57-mer synthetic DNA (5'-AAGCTTCTAGAGATCCGTCA-N $\mathrm{N}_{6}-\mathrm{AAAG}^{-}$ $\mathrm{N}_{6}$-GTCGCACGACCCTGGTCGTAA-3') containing an AAAG core flanked by six random nucleotides on each side and two primers ( $F$ and $R$ ': 5'--TTACGACCAGGGTCGTGCGAC-3') was used to generate a 57-bp DNA mixture by PCR amplification. Fifty-one individual clones were obtained after six rounds of selection, and the inserted sequences were determined.

\section{Gel retardation assay}

A gel retardation assay was carried out as previously described (Seki et al., 1996). Probe DNAs were labeled with $\left[\gamma-{ }^{32} \mathrm{P}\right]-\mathrm{ATP}$ and $\mathrm{T} 4$ polynucleotide kinase, then incubated with 500 or $1,000 \mathrm{ng}$ of purified GST-PsDof1 fusion protein in a $1 \mathrm{x}$ binding buffer $(25 \mathrm{mM}$ HEPES-KOH, $100 \mathrm{mM}$ $\mathrm{KCl}, 1 \mathrm{mM}$ DTT, $0.1 \%$ NP40, 5\% glycerol; pH 7.5) containing $2 \mu \mathrm{g}$ of poly (dI- dC: $\mathrm{dI}-\mathrm{dC}$ ) in a total volume of $10 \mu \mathrm{l}$. Mixtures were fractionated on a $4 \%$ polyacrylamide gel (acrylamide:bisacrylamide, 19:1) with $0.5 \times$ TBE buffer at $100 \mathrm{~V}$ at $4{ }^{\circ} \mathrm{C}$. Gels were dried under a vacuum and exposed to $X$-ray film at room temperature for 17-24 h. For competition assays, a 30 - or 90-fold excess of unlabeled synthetic DNAs was added to the binding mixture. For inhibition assay by the metal chelator, 2, 5, or
$10 \mathrm{mM} 1,10$ phenanthroline was added to the binding mixture. To prepare DNA fragments corresponding to the promoter region of PsDofl gene, we amplified DNA fragments with two sets of DNA primers (P1 and P3: 5' TGAAATGAGGTTGGTAGTGGAGAG-3'; P2 and P4: 5'-CATTTTTCACTCTCTCCATTCCTC-3'), then digested them with EcoRI, AluI, AfaI, and BamHI. After separation of each DNA fragment with polyacrylamide gel electrophoresis, DNA fragments F1-F4 were extracted and labeled prior to the binding assay.

\section{Results}

Structural analysis of a cDNA clone for PsDof1 and its gene expression

To analyze the molecular mechanism of elicitor-induced transcription of defense-related genes, we constructed a cDNA library from pea epicotyls treated with an elicitor from Mycosphaerella pinodes for $5 \mathrm{~h}$ and found a unique cDNA clone, E84. As shown in Fig. 1A, DNA sequence analysis of $E 84$ revealed that the cDNA insert is 1,269 bp long, and includes a 21 -nucleotide poly - A tail. The E84 cDNA clone seems to possess the entire coding region (or almost all of it), because the size of the cDNA is consistent with the estimated size of the mRNA detected in a Northern-blot hybridization experiment (described below). The largest open reading frame spans 283 amino acids, from which a protein of $31.6 \mathrm{kDa}$ is predicted. Database searches revealed that the deduced amino acid sequence of E84 exhibits high homology to a recently discovered Dof class of DNA-binding proteins (Yanagisawa, 1996); thus, E84 was renamed PsDof1. The Dof domain in PsDof1 is located near the $\mathrm{N}$-terminus of a 52-amino-acid stretch (37-88 in Fig. 1), like other Dof proteins. The amino acid sequence of the Dof domain was highly conserved with other Dof domains (Fig. 1B), whereas the sequence outside the Dof domain did not share high homology with any other proteins in the database. The most homologous protein is a putative Dof protein encoded by At2g28510 of $A$. thaliana, which was registered by the gemonic sequencing project. PsDof1 and At2g28510 showed 35.9\% identity and $71.4 \%$ similarity in amino acid sequences, including the sequence of the conserved Dof domain. The function and expression of At $2 \mathrm{~g} 28510$ is not yet characterized.

The organ-specific expression of PsDof1 was examined by Northern - blot hybridization. PsDof1 mRNA (ca. $1.3 \mathrm{~kb}$ ) was most abundant in stems, then in roots and leaves (data not shown). Although the cDNA clone for PsDof1 was initially isolated as 
A

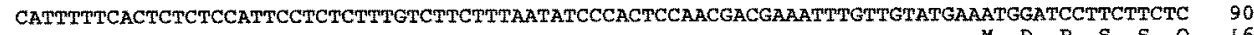

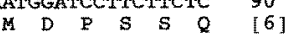

AGCAAATGTCAAGGCAATCATCAATGGAAACATGTTGGTTTGTTCAAAAGAACAGCAAGAAAGCAAACCCAAGCCTCAGCCGGAACAAG 180

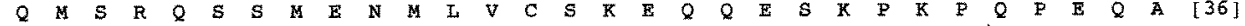

CTCTGAATGTCCGAGATGTGATTCGACCAACACCAAATTCTGTTACTACAACAATTACAGTCTTACTCAGCCGAGATATTWCTGCAAAT 270

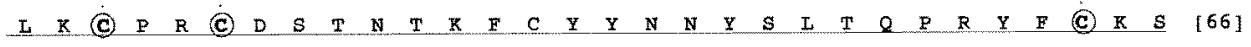

CTTGCCGGAGATATTGGACCAAAGGTGGAACATTGAGGAATGTTCCTGTTGGTGGCGGGTGTAGGAAGAACAAAAGATCATCGTCTTCGA 360

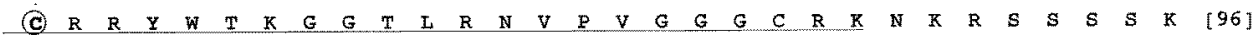

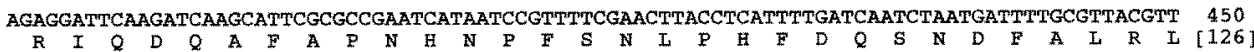

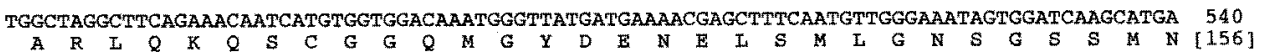

ACCAGTCGATGAGCATAAATCATGGGTTTATGGATGCGATMAGAGTGGTTTATTCCTTGGAAATGGAATGCATTATAATAATAGTGTMC 630

Q S M S I N H G F M D A I R S G L F L G N G M H $Y$ N N S V $\quad$ [186]

AAAATATGTATGGTGGTGGCTATGGAAATGGTGACAATGGAGAAGTGAATAGTGGAAACAACAATTGTGGGGTTAGTGAAGAGATGATGT 720

$\mathbb{N} M \quad Y G G G G Y G$ G G D N G E V N S G N N N C G V S E

TTAATTATGATCAAGAAATGAGCCATTGCAATGCTGCTATTAACATGAAGCAAGAGCAAAGGAAAGTAGGGTTTTTGGTGGTTTTCCAT 810

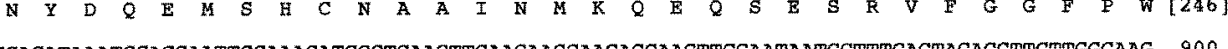

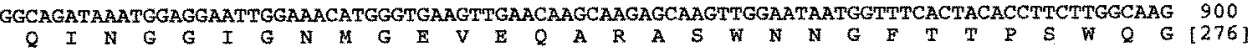

GGCTTCTTCATAGTCCTCTAATGTAGAATCAAAAGATAATATGATYTTAAATTGCGGTCTGCAGTTGAAGTTGAGAAATGCAGCTACTAC 990

I I H $S$ P L $M$ *

$[283]$

AGATGAAGTTGTCATTGCAGACTGCAATTTAGAAATTTAGAAGTGGTTGTATAAATTWGCCTAATGTTTGACAAAATTATATTGGTTTA 1080 GGGTTAATTAAATTTTCAGTCCTCTTGAGTAGAATTGGGTTGATAGAGATTTGATGCATTIAGAAATGGATCAAATTCTATTCTCTACCT 1170

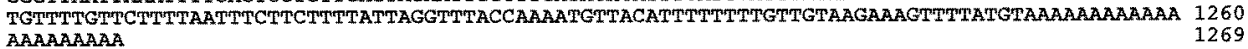

B

\begin{tabular}{|c|c|c|c|}
\hline PsDof1 & LKCPRCDSTNTKFCYYNNYSLTQPRYFCKSCRRYWTKGGTLRNVPVGGGCRK & Identity & Reference \\
\hline BBF1 & 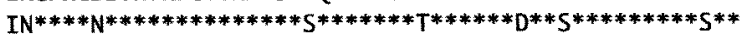 & $(84.6 \%)$ & [4] \\
\hline tOBP1 & 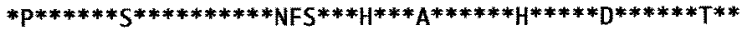 & $(80.8 \%)$ & [24] \\
\hline tDAG1 & $* \mathrm{~N} * * * * \mathrm{~N} * * * * * * * * * * * * * * * * * * * * * * \mathrm{G} * * * * * * \mathrm{E} * * 5 * * * * * * * * \mathrm{~S} S * *$ & $(86.5 \%)$ & [11] \\
\hline $\mathrm{ZmDof1}$ & $\mathrm{DP} * * * * \mathrm{~A} * \mathrm{RD} * * * * * * * * * \mathrm{NTS} \mathrm{S}^{* * *} \mathrm{H}^{* * *} \mathrm{G} * * * * * * * * * * * * * * * * * * * \mathrm{~T} * *$ & $(78.8 \%)$ & [20] \\
\hline ZmDof2 & $\mathrm{DP} * * * * \mathrm{G} * \mathrm{RD} * * * * * * * * * \mathrm{NTS} \mathrm{S}^{* * *} \mathrm{HL} * * * * * * * * * * * * \mathrm{~S}^{* * * * * * * * *} \mathrm{~T} * *$ & $(76.9 \%)$ & [18] \\
\hline ZmDof3 & $* * * * * * * * * * * * * * * * * * * \mathrm{H}^{* *} \mathrm{RA} \mathrm{A}^{* * * * * * \mathrm{R} * * \mathrm{~A} * * * * * * * * * \mathrm{Y}^{*}}$ & $(86.5 \%)$ & [1.8] \\
\hline ZmPBF & $* * * * * * * * \mathrm{~N} * * * * * * * * * * * M S * * * * * * * A * * * * * * H * * * * * * * * I * * * * * *$ & $(88.5 \%)$ & [16] \\
\hline BPBF & 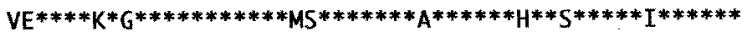 & $(80.8 \%)$ & [19] \\
\hline AOBP & $* p * * * * N * M E * * * * * * * * * N V N * * * H^{* * *} A^{*} Q^{* * * * E * * *} I^{* * * * * *} A^{*} R^{* *}$ & $(73.1 \%)$ & [9] \\
\hline
\end{tabular}

Fig. 1 Structural analysis of PSDof1 cDNA. (A) The nucleotide sequence of PsDofl cDNA numbered from the $5^{\prime}$ end. The deduced amino acid sequence of PsDof1 protein is shown below the nucleotide sequence, and is numbered in parentheses. The Dof domain is underlined, and the four cysteine residues putatively involved in $\mathrm{Zn}^{24}$ coordination are circled. The asterisk indicates the stop codon. (B) Sequence conservation through the Dof domain. The amino acid sequence of the Dof domain of PsDof1 is shown aligned with other Dof proteins. Asterisks are the amino acids that are identical to the corresponding amino acid of PsDof1. Numbers in parentheses on the right indicate the percentage of sequence identity with PsDof1 within the Dof domain. The four cysteine residues that putatively coordinate to $\mathrm{Zn}^{2+}$ are shown by arrowheads. The nucleotide sequence of PSDof1 cDNA has been submitted to DDBJ, GenBank, and EMBL databases under accession number AB026297.

a candidate for an elicitor-inducible gene, PsDof 1 was expressed slightly after $6 \mathrm{~h}$ treatment with elicitor (data not shown).

\section{DNA - binding sequence of PsDofl protein}

To examine the DNA - binding ability of PsDof1 protein and to identify its binding motif, GSTPsDof1 fusion protein was prepared using an $E$. coli expression system as described in the Materials and Methods. Two rounds of a random binding-site selection assay revealed that GST-PsDof1 protein binds 51 individual sequences. The sequences of selected DNAs are listed in Fig. 2A, where they are aligned to match the sequence with an AAAG core.
The putative optimal PsDof1 binding sequence deduced from the 51 independent sequences is TTT/cT/cT/gT/aAAAGTGT/cTTT (Fig. 2B). There are $\mathrm{T} / \mathrm{C}$-rich sequences around the $\mathrm{AAAG}$-core motif, and AAAG or its complementary sequence CTTT were found frequently beside the central AAAG-core sequence (in 25 out of 51 clones, Fig. 2A).

A gel retardation assay was performed to determine if PsDof1 binds specifically with the AAAG containing sequences. The binding-site selection experiment (Fig. 2A) showed that individually isolated clones (BS4 and BS37) have an identical sequence, which shows high homology to the puta- 
tive optimal PsDof1 binding sequence (Fig. 2B). Therefore, we synthesized a double-stranded 16 bp oligonucleotide, BS4/37, as a probe (Fig. 3A).

As shown in Fig. 3B, a clear, retarded band was observed after incubation of the BS4/37 with GSTPsDof1 fusion protein (lanes 2 and 3 ) but not without GST-PsDof1 fusion protein (lane 1) or with GST protein for the control (lanes 13 and 14). Adding a 30 -fold molar excess of unlabeled BS4/37 as a competitor fully inhibited the binding (Fig. 3C, lane 2). Because sequences with an AAAG core were always found in the DNA fragments after binding-site selection experiments, we modified the sequence of AAAG by substituting $\mathrm{AgAc}$ as $\mathrm{m} 2$ (Fig. 3A). The $\mathrm{m} 2$ did not form any binding complex with GST-PsDof1 fusion protein (Fig. 3B, lanes 8 and 9). Furthermore, a 90-fold excess of $\mathrm{m} 2$ did not compete in the binding of
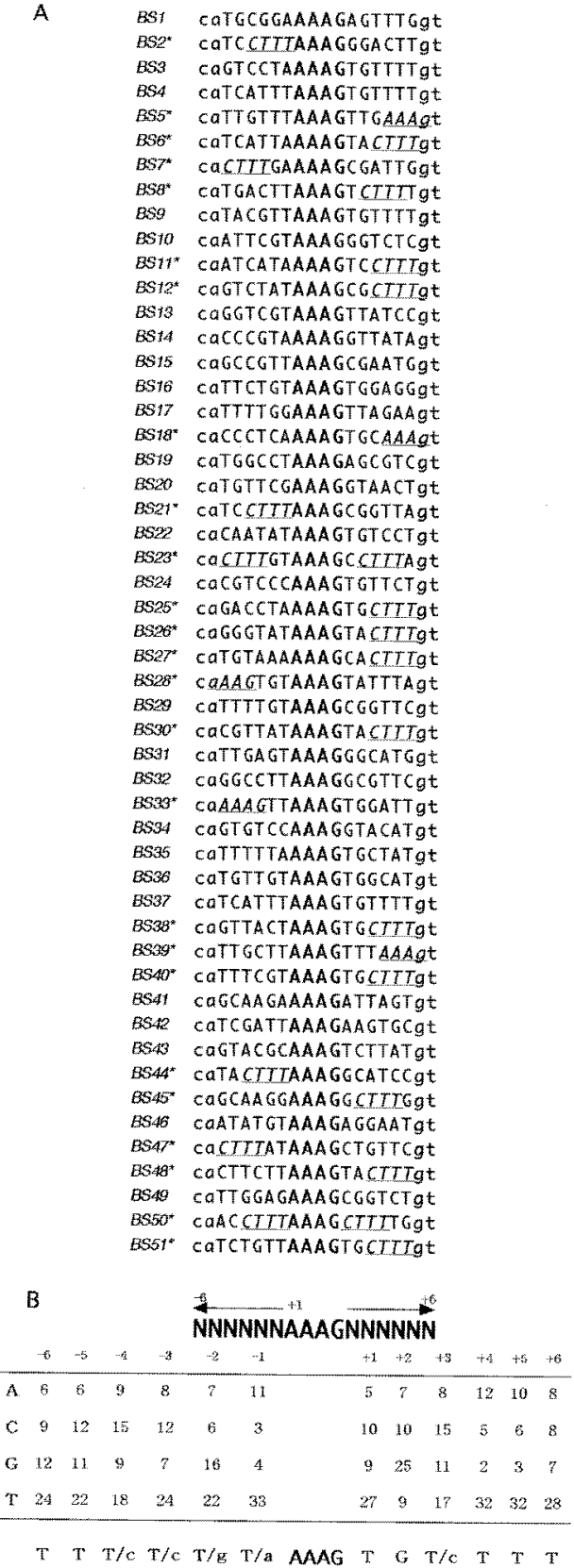

labeled BS4/37 and GST-PsDof1 fusion protein (Fig. 3C, lanes 6 and 7). These observations suggest that the AAAG sequence is indispensable for the specific binding of PsDof1.

To investigate whether sequences flanking the AAAG-core motif contribute to DNA-binding of PsDof1, three nucleotide substitutions either up - or downstream of the AAAG-core motif were introduced (Fig. 3A). The modification of the 5' flanking TTT sequence to gcg (Fig. 3A, m1) reduced (but did not eliminate) the binding of GST-PsDof 1 (Fig. 3B, lanes 5 and 6). Furthermore, the unlabeled synthetic DNA $\mathrm{m} 1$ effectively competed in the complex formation of BS4/37 and GST-PsDof1, although competition efficiency was somewhat lower than that of BS4/37 (Fig. 3C, lanes 2 and 4). On the other hand, the synthetic DNA m3, in which the 3' flanking TGT sequence was modified to aaa, exhibited only slight signals of a binding complex with GST-PsDof1 fusion protein (Fig. 3B, lane 12), whereas an excess of $\mathrm{m} 3$ significantly reduced the complex formation of BS4/37 with GST-PsDof1 (Fig. 3C, lanes 8 and 9). Thus, TTT (the 5' flanking sequence of $\mathrm{AAAG}$ ) was not necessary for the PsDof1-binding affinity, while TGT (the 3' flanking sequence of AAAG) contributed to the increased binding affinity of GST-PSDof1.

\section{Zinc requirement for DNA-binding activity}

Since PsDof1 may bind to DNA through the Dof domain, a putative zinc-finger DNA-binding domain, we investigated whether zinc coordination is

Fig. 2 Selection of PsDof 1 - binding sequences. (A) Fifty-one selected binding sequences were determined. An independent binding sequence indicates that the sequence existed in the plasmid vector prepared from independently isolated clones. Upper-case letters indicate sequences derived from random sequences, except for the prefixed AAAG sequence which is indicated by bold letters (see the Materials and Methods). Lower-case letters on both sides indicate sequences within the primer regions. Binding sequences containing additional AAAG or CTTT sequences are indicated by asterisks, and the corresponding regions are underlined. (B) The nucleotide frequency of each position around the prefixed AAAG core is shown. The common nucleotide(s) for each position are indicated at the bottom of the panel. The upper-case letters represent the most common nucleotide(s), and the lower-case letters represent a relatively frequent nucleotide; the AAAG-core sequence is indicated in bold. 
A

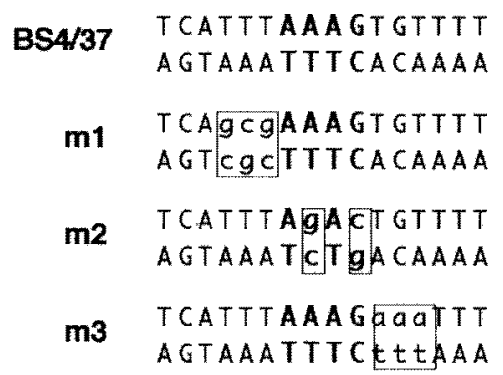

B

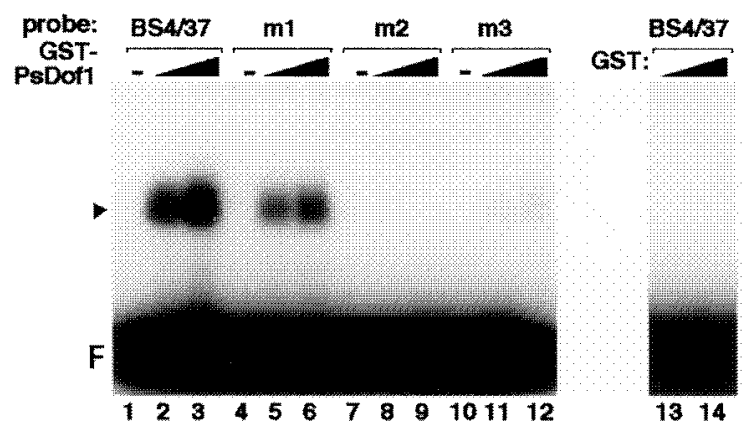

C
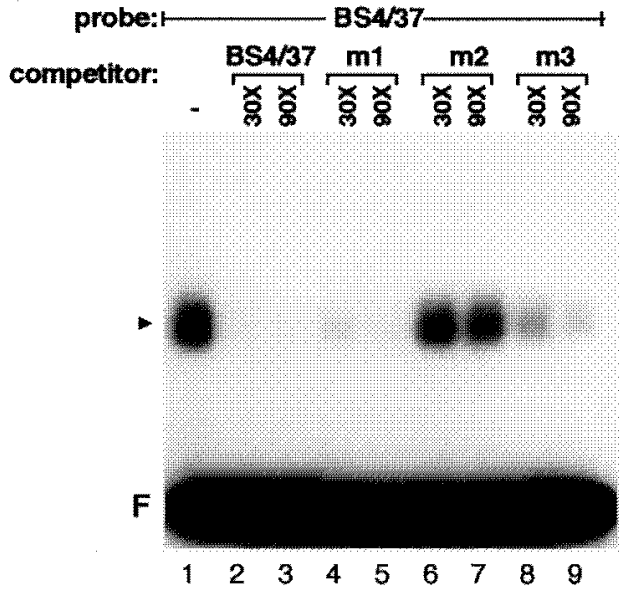

Fig. 3 DNA-binding specificity of GST-PSDof1. (A) Synthetic DNA sequence corresponding to the clones BS4 and BS37 and three different derivatives are shown as BS4/37, $\mathrm{m} 1, \mathrm{~m} 2$, and $\mathrm{m} 3$, respectively. The substituted nucleotides were boxed. (B) Gel retardation assay using each synthetic DNA shown above as a probe. Labeled synthetic DNAs were incubated in the absence $(-)$ or with increasing (500 and $1,000 \mathrm{ng}$, indicated by triangles) amounts of purified GSTPsDof1 or GST control protein (lanes 13 and 14). (C) Binding competition assay using BS $4 / 37$ as a probe. A 30 - or 90-fold excess of each synthetic competitor was added to the probe DNA. Arrowhead and $F$ denote the positions of the retarded band and free probe, respectively.

involved in the DNA binding activity of this protein. We tested the inhibition of complex formation

\section{7}

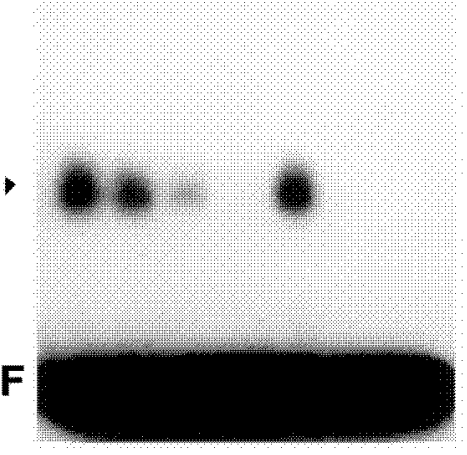

Fig. 4 Inhibition of DNA- binding of PsDof1 by 1,10 - phenanthroline. The labeled DNA fragment, BS4/37, and GST-PsDof1 (500 ng) were incubated without (lane 1) or with 1,10-phenanthroline (lane 2: $2 \mathrm{mM}$; lane 3:5 mM; lane 4: 10 $\mathrm{mM})$. The loss of DNA-binding activity caused by 1,10 - phenanthroline (lane 4 ) was restored by the addition of $10 \mathrm{mM} \mathrm{ZnCl}_{2}$ (lane 5) but not by $10 \mathrm{mM} \mathrm{MgCl}_{2}$ (lane 6) or $10 \mathrm{mM} \mathrm{CaCl}_{2}$ (lane 7). Closed arrowhead and $\mathrm{F}$ denote the positions of the retarded band and free probe, respectively.

by a metal chelator, 1,10 -phenanthroline that prefers $\mathrm{Zn}^{2+}$ in the gel retardation assay. As shown in Fig. 4, the formation of the complex of GSTPsDof1 and BS4/37 was effectively inhibited by the addition of 1,10-phenanthroline. We confirmed that the chelator did not inhibit the binding activity via a nonspecific mechanism: the DNA-binding activity could be restored by the addition of $\mathrm{Zn}^{2+}$ after inhibition by the chelator (Fig. 4, lane 5), but not by the addition of $\mathrm{Mg}^{2+}$ or $\mathrm{Ca}^{2+}$ (Fig. 4, lanes 6 and 7). Thus, zinc coordination is required for DNA-binding activity of PsDof1.

\section{Promoter region of PsDof1 gene}

To characterize the structure of the PsDof1 gene, we first isolated the corresponding genomic phage clone from the commercially available pea genomic DNA library using the PsDofl cDNA sequence as a probe. Then, using the DNA sequence information obtained, we further isolated the corresponding region from the pea cultivar Midoriusui by PCR. As shown in Fig. 5, the 1,684 bp sequence of a PCRamplified fragment containing the approximately $1.4-\mathrm{kb}$ promoter region was determined. There is a $120-$ bp intron between the sixth and seventh amino acids.

\section{Specific binding of PSDof1 to PSDof1 promoter}

To investigate the possible interaction between PsDof1 and the promoter region of the PsDof1 gene, 


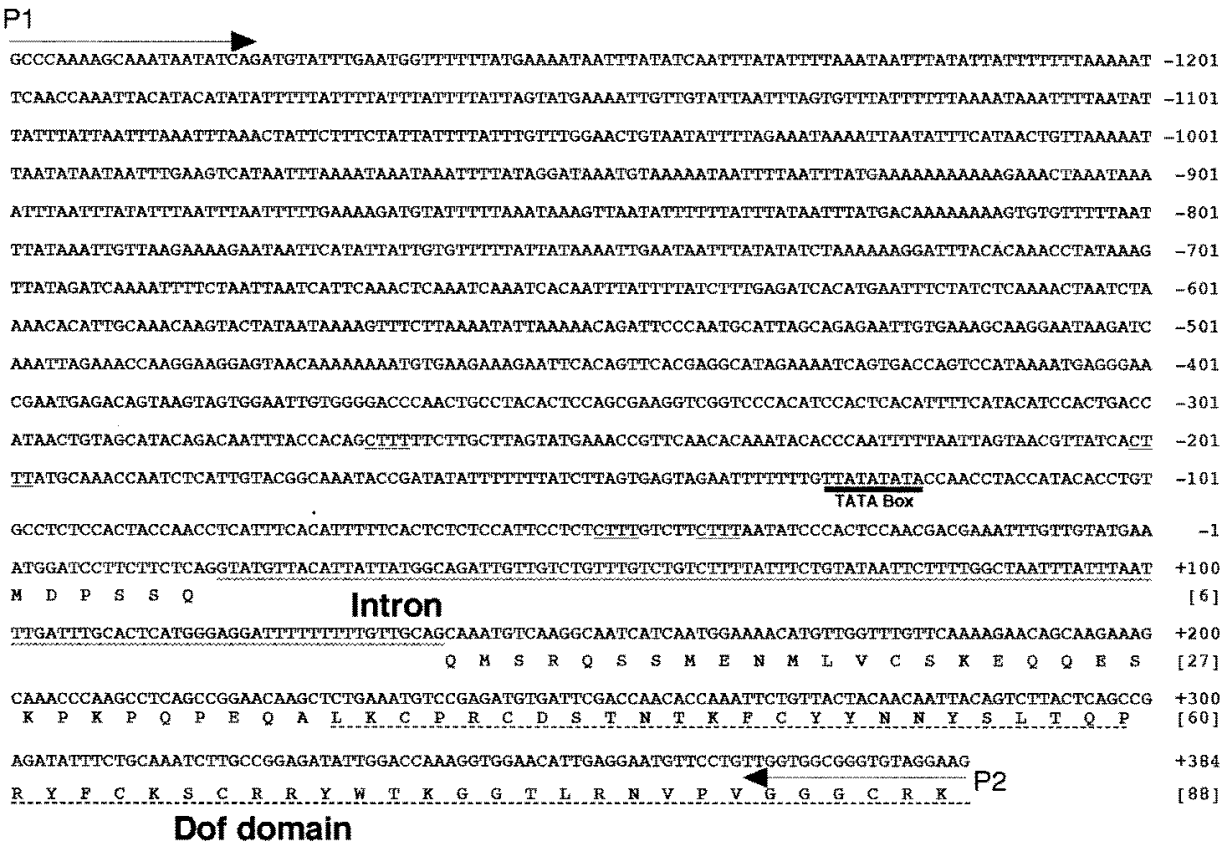

Fig. 5 Structural analysis of PsDof1 gene. The nucleotide sequence of the PsDof1 gene containing the promoter region is shown. The nucleotides are numbered from the putative translation start site, A, as +1 . The 5' end of PsDof 1 cDNA (E84) is indicated by the dot at position - 74. The amino acid sequence of PsDof1 is also shown below the nucleotide sequence, and is numbered in parentheses. The nucleotide sequences for the TATA box and intron and amino acid sequence for the Dof domain are indicated by a thick line, a wavy line, and a dotted line, respectively. The thin underlines indicate the CTTT sequences indicated in Fig. 6A as bold vertical lines. The two arrows represent the primer sequences used for PCR-mediated amplification of this region as described in the Materials and Methods. The nucleotide sequence of the PsDof1 gene has been submitted to DDBJ, GenBank, and EMBL databases under accession number AB074443.

we carried out the DNA-protein binding assay with gel retardation experiments. Four labeled DNA fragments containing either promoter or $5^{\prime}$ - untranslated regions of the PSDof1 gene were prepared (Fig. 6A). The results clearly demonstrate that the fragments F2 and F4 formed complexes with GST PsDof1 fusion proteins, but not with GST proteins (Fig. 6B). As indicated in Fig. 6A, both F2 and F4 contained putative PsDof1-binding sequences (AAAG or CTTT), but neither F1 nor F3 contained such sequences. Thus, these sequences were thought be involved in the formation of the complex.

\section{Discussion}

In this study, we isolated a cDNA clone designated $P s D o f 1$. This gene encodes a novel type of transcription factor that has a Dof DNA-binding domain with DNA-binding ability. Random binding-site selection and gel retardation assays demonstrated that PsDof1 binds specifically to DNA sequences with an AAAG-core motif, and sequences flanking the $\mathrm{AAAG}$ core can also affect the binding affinity (Fig. 2 and 3 ). Because the Dof domain was identified as the DNA-binding domain in maize Dof1 (Yanagisawa, 1995), and the Dof domain is highly conserved among the Dof proteins (Fig. 1B), all members of the Dof protein family may recognize similar DNA sequences. Indeed, maize Dof proteins Dof1, Dof2, and Dof3 recognize the (A/T)AAAG sequence as the core motif (Yanagisawa, 1996). The target sequences of Arabidopsis Dof protein OBP1 also contain the AAAG motif (Zhang et al., 1995; Chen et al., 1996). Another maize Dof protein, PBF, and its barley homolog, BPBF, bind a P-Box motif: TGTAAAG (VicenteCarbajosa et al., 1997; Mena et al., 1998). The tobacco Dof protein BBF1 binds a TAAAGT sequence (De Paolis et al., 1996). Our gel shift retardation assay revealed that not only the AAAG core motif but also a TGT sequence located just downstream of the core motif are essential for DNA binding of PsDof1 (Fig. 3). Furthermore, in random binding - site selection assays, we frequently found a CTTT sequence motif beside the AAAG-core sequence (Fig. 2). This result indicates that the presence of two potential binding sites could increase the binding efficiency to PsDof1 proteins. 

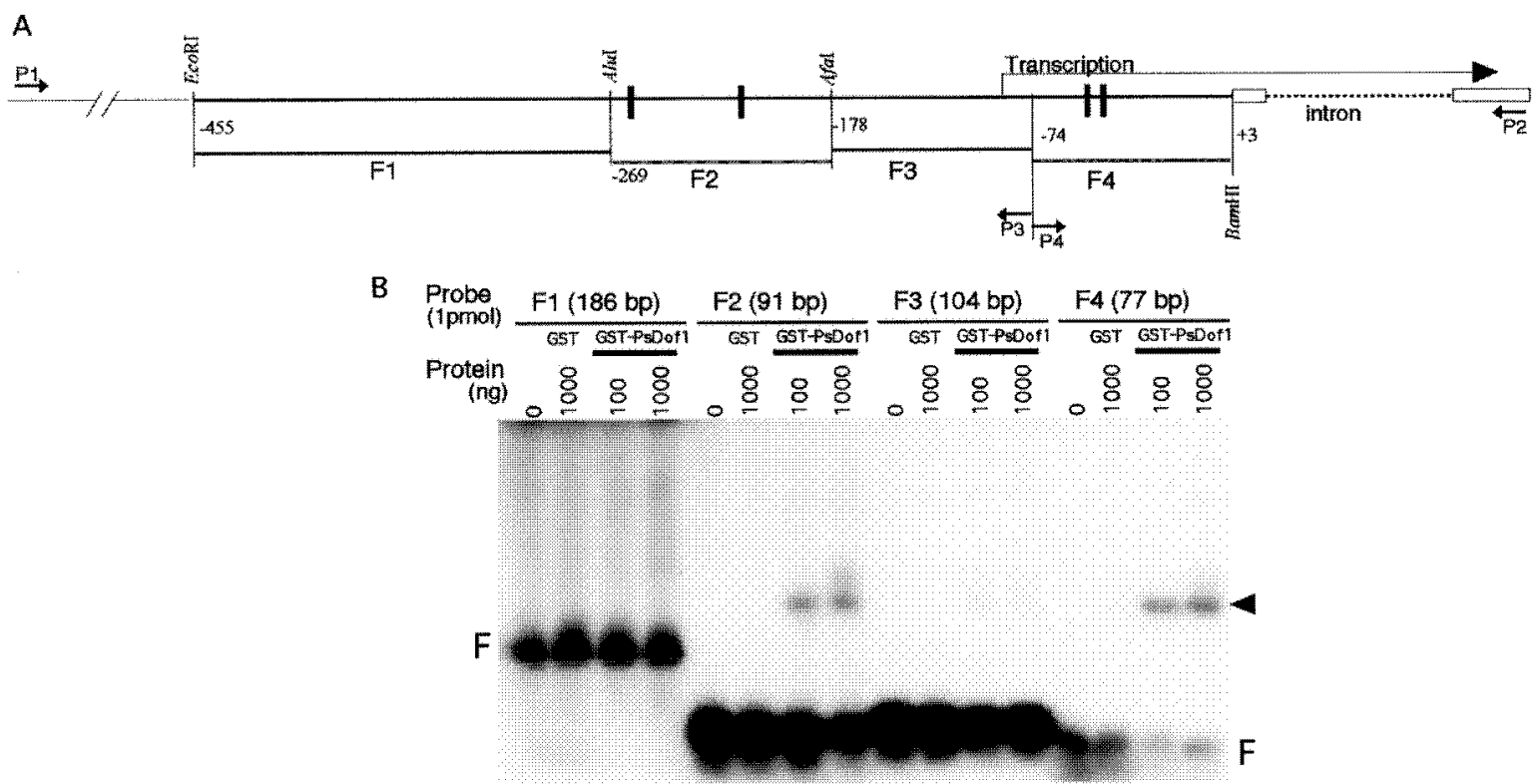

Fig. 6 DNA binding of PsDof1 to its promoter sequence. (A) The promoter and 5'untranslated region of PsDofI was divided into four fragments, designated F1-F4. Fragments F2 and F4 contain two putative PsDof1 binding sequences, CTTT, and are indicated as bold vertical lines. The position of the translation start site, $A$, is numbered as +1. The regions for open reading frames in two exons are indicated as boxes, and the intron is shown as a dotted line. (B) The DNA-binding activity of each DNA fragment was examined by gel retardation assay. Each 1 pmol of labeled DNA was incubated in the absence or presence (100 or 1,000 ng) of purified GST-PSDof1 or GST control protein. Arrowhead and F denote DNA-protein complexes and free DNA probes, respectively. The preparation of each DNA fragment is described in the Materials and Methods.

Although all Dof proteins recognize highly similar sequences, as described above, Dof proteins have been shown to be involved in a variety of signal-responsive and/or tissue-specific gene expressions in plants. For example, the maize Dof1 and Dof 2 proteins are implicated in the light-regulated activation of the gene for the C4-type phosphoenolpyruvate carboxylase of maize (Yanagisawa and Sheen, 1998). Another maize Dof protein, PBF, and its barley homolog, BPBF, are involved in the endosperm-specific expression of seed-storage protein genes (Vicente-Carbajosa et al., 1997; Mena et al., 1998). The tobacco Dof protein BBF1 is involved in the tissue-specific and auxin-responsive expression of the rolB gene of Agrobacterium rhizogenes (De Paolis et al., 1996; Baumann et al, 1999), and the Arabidopsis DAGI gene controls seed germination (Papi et al., 2000). Recently it was reported that the expression of Arabidopsis Dof proteins, called OBP1, -2 , and -3 , were induced by the plant-defense signaling compound salicylic acid (Kang and Singh, 2000). Furthermore, Chen et al. (1996) also found that OBPs could interact with OBF4 protein, a bZIP factor that binds ocs elements, and stimulate the binding of OBF4 to the ocs element in the Arabidopsis glutathione S-transferase-6 (GST6) gene promoter. Ocs elements are activated by salicylic acid (Zhang and Singh, 1994; Yang et al., 1997), and an ocs element in the Arabidopsis GST6 gene promoter has also been shown to be involved in the responsiveness of this gene to salicylic acid (Chen and Singh, 1999). These observations suggest that certain members of the Dof-type DNA-binding proteins are an emerging group of transcription factors that play a role in the regulation of defense genes in a wide range of plant species. Although PsDof 1 cDNA was isolated from the library of elicitor-treated pea epicotyls, the induction of PSDof1 by the elicitor was not clearly observed. Thus, it is still unclear whether PsDof1 contributes to the transcriptional activation of some elicitor-inducible genes.

Interestingly, we found that PsDof1 protein strongly binds in vitro to $\mathrm{AAAG}$-containing sequences present in the promoter region of PSDofI itself. The evidence suggests that the PsDof 1 gene is regulated by PsDof1 protein itself. Such autoregulation has been reported in some plant genes. For example, in response to a fungal elicitor, one of the plant-specific zinc-finger-type transcription fac- 
tors, parsley WRKY1 protein, binds W-box promoter elements in not only $P R-10$ but also WRKYI genes, and activates their transcriptions (Eulgem $e t$ al., 1999). On the other hand, a TFIIIA-type transcription factor, wheat WZF-1, was reported as a transcriptional repressor for the $W Z F-1$ gene (Sakamoto et al., 1996). A transient transfection assay revealed that WZF-1 activates the histone $\mathrm{H} 3$ promoter via WZF-1 binding elements in wheat, whereas the results of the cotransfection experiments showed that the expression of WZF-1 by an effector plasmid significantly repressed $W Z F-1$ promoter-mediated reporter gene expression in tobacco (Sakamoto et al., 1996). Thus, WZF-1 might possess bifunctional activities by regulating plant genes both positively and negatively.

Further studies are needed on the role of the PsDof1 gene in plant gene regulation, especially in defense responses. The identification of the target genes of PsDof1 protein and the transcription factors that regulate $P_{S} D o f 1$ gene expression will reveal the downstream and upstream signal transduction pathways, respectively.

\section{Acknowledgement}

This work was supported in part by a Grant-inAid for Scientific Research on Priority Areas (No. 12460023) from the Ministry of Education, Culture, Sports, Science and Technology and the Japan Society for the Promotion of Science.

\section{References}

Baumann, K., De Paolis, A., Costantino, P., Gualberti, G., 1999. The DNA binding site of the Dof protein NtBBF1 is essential for tissue-specific and auxin-regulated expression of the rolB oncogene in plants. Plant Cell, 11: $323-333$.

Chen, W., Singh, K. B., 1999. The auxin, hydrogen peroxide and salicylic acid induced expression of the Arabidopsis GST6 promoter is mediated in part by an ocs element. Plant J., 19: 667-677.

Chen, W., Chao, G., Singh, K. B., 1996. The promoter of a $\mathrm{H}_{2} \mathrm{O}_{2}$ - inducible, Arabidopsis glutathione $\mathrm{S}$ - transferase gene contains closely linked OBF- and OBP1-binding sites. Plant J., 10: 955-966.

De Paolis, A., Sabatini, S., De Pascalis, L., Costantino, P., Capone, I., 1996. A rolB regulatory factor belongs to a new class of single zinc finger plant proteins. Plant J, 10: $215-223$.

Eulgem, T., Rushton, P. J., Schmelzer, E., Hahlbrock, K., Somssich, I. E., 1999. Early nuclear events in plant defence signalling: rapid gene activation by WRKY transcription factors. EMBO J., 18: $4689-4699$.

Hyde-DeRuyscher, R. P., Jennings, E., Shenk, T., 1995. DNA binding sites for the transcriptional activator/repressor YY1. Nucleic Acids Res., 23: 44574465.
Ichinose, Y., Hisayasu, Y., Sanematsu, S., Ishiga, Y., Seki, H., Toyoda, K., Shiraishi, T., Yamada, T., 2001. Molecular cloning and functional analysis of pea cDNA E86 encoding homologous protein to hypersensitivityrelated hsr203J. Plant Sci, 160: 997-1006.

Kang, H.-G., Singh, K. B., 2000. Characterization of salicylic acid-responsive, Arabidopsis Dof domain proteins: overexpression of OBP3 leads to growth defects. Plant J., 21: 329-339.

Kisu, Y., Ono, T., Shimofurutani, N., Suzuki, M., Esaka, M., 1998. Characterization and expression of a new class of zinc finger protein that binds to silencer region of ascorbate oxidase gene. Plant Cell Physiol., 39: 1054-1064.

Mena, M., Vicente-Carbajosa, J., Schmidt, R., Carbonero, P., 1998. An endosperm-specific DOF protein from barley, highly conserved in wheat, binds to and activates transcription from the prolamin - box of a native $B$ - hordein promoter in barley endosperm. Plant J., 16: 53 $-62$.

Papi, M., Sabatini, S., Bouchez, D., Camilleri, C., Costantino, P., Vittotioso, P., 2000. Identification and disruption of an Arabidopsis zinc finger gene controlling seed germination. Genes Dev., 14: 28-33.

Riechmann, J. L., Heard, J., Martin, G., Reuber, L., Jiang, C., Keddie, J., Adam, L., Pineda, O, Ratcliffe, O. J., Samaha, R. R., Creelman, R., Pilgrim, M., Broun, P., Zhang, J. Z., Ghandehari, D., Sherman, B. K., Yu, G., 2000. Arabidopsis transcription factors: genome-wide comparative analysis among eukaryotes. Science, 290: $2105-2110$.

Sakamoto, A., Omirulleh, S., Nakayama, T., Iwabuchi, M., 1996. A zinc-finger-type transcription factor WZF-1 that binds to a novel cis-acting element of histone gene promoters represses its own promoter. Plant Cell Physiol, 37: 557-562.

Seki, H., Ichinose, Y., Kato, H., Shiraishi, T., Yamada, T., 1996. Analysis of $c i$ - regulatory elements involved in the activation of a member of chalcone synthase gene family (PsChs1) in pea. Plant Mol. Biol., 31: 479- 491 .

Takatsuji, H., 1998. Zinc-finger transcription factors in plants. Cell. Mol. Life Sci, 54: 582-596.

Vicente-Carbajosa, J., Moose, S. P., Parsons, R. L., Schmidt, R. J., 1997. A maize zinc--finger protein binds the prolamin box in zein gene promoters and interacts with the basic leucine zipper transcriptional activator Opaque2. Proc. Natl. Acad. Sci. U. S. A., 94: 7685 7690 .

Yanagisawa, S., 1995. A novel DNA-binding domain that may form a single zinc finger motif. Nucleic Acids Res., 23 : $3403-3410$.

Yanagisawa, S., 1996. Dof DNA - binding proteins contain a novel zinc finger motif. Trends Plant Sci., 1: 213-214.

Yanagisawa, S., Izui, K., 1993. Molecular cloning of two DNA-binding proteins of maize that are structurally different but interact with the same sequence motif. J. Biol. Chem., 268: 16028-16036.

Yanagisawa, S., Sheen, J., 1998. Involvement of maize Dof zinc finger proteins in tissue-specific and light-regu- 
lated gene expression. Plant Cell, 10: 75-89.

Yang, Y., Shah, J., Klessig, D. F., 1997. Signal perception and transduction in plant defense responses. Genes Dev., 11: 1621-1639.

Zhang, B., Singh, K. B., 1994, ocs element promoter sequences are activated by auxin and salicylic acid in
Arabidopsis. Proc. Natl. Acad. Sci, U. S. A., 91: $2507^{-}$ 2511.

Zhang, B., Chen, W, Foley, R. C., Buttner, M., Singh, K. B., 1995. Interactions between distinct types of DNA binding proteins enhance binding to ocs element promoter sequences. Plant Cell, 7: 2241-2252. 